\title{
RESEARCH
}

\section{HIF 1 inhibits STAR transcription and testosterone synthesis in murine Leydig cells}

\author{
Xueting Wang1,2, Zhiran Zou1,2, Zhihui Yang1,2, Shan Jiang1,2, Yapeng Lu1,2, Dan Wang1,2, Zhangji Dong2,3, Sha Xu \\ and Li Zhu'1,2 \\ 1'Institute of Nautical Medicine, Nantong University, Nantong, Jiangsu, China \\ ${ }^{2}$ Co-innovation Center of Neuroregeneration, Nantong University, Nantong, Jiangsu, China \\ 3Key Laboratory of Neuroregeneration of Jiangsu and Ministry of Education, Nantong, Jiangsu, China \\ ${ }^{4}$ Medical College of Soochow University, Suzhou, Jiangsu, China
}

Correspondence should be addressed to L Zhu: zhuli85051796@163.com

\begin{abstract}
Hypoxia-inducible factor-1 (HIF1) is a critical transcription factor involved in cell response to hypoxia. Under physiological conditions, its 'a' subunit is rapidly degraded in most tissues except testes. HIF1 is stably expressed in Leydig cells, which are the main source of testosterone for male, and might bind to the promoter region of steroidogenic acute regulatory protein (STAR), which is necessary for the testosterone synthesis, according to software analysis. This study aims to identify the binding sites of HIF1 on Star promoter and its transcriptional regulation of STAR to affect testosterone synthesis. Testosterone level and steroid synthesis-related proteins were determined in male Balb/C mice exposed to hypoxia $\left(8 \% \mathrm{O}_{2}\right)$. While HIF1 was upregulated, the testosterone level was significantly decreased. This was further confirmed by in vitro experiments with rat primary Leydig cells or TM3 cells exposed to hypoxia $\left(1 \% \mathrm{O}_{2}\right), \mathrm{CoCl}_{2}$ or DFX to raise HIF1. The decline of testosterone was reversed by pregnenolone but not CAMP, indicating the cholesterol transport disorder as the main cause. In agreement, STAR expression level was decreased in response to HIF1, while 3b-hydroxysteroid dehydrogenase, 17b-hydroxysteroid dehydrogenase and p450scc did not exhibit significant changes. By ChIP, EMSA supershift and dual-luciferase reporter assays, HIF1 was found to bind to the Star promoter region and repress the expression of STAR. Mutation assays identified three HIF1-binding sites on mouse Star promoter. These findings indicate that HIF1 represses STAR transcription through directly binding to the Staar promoter at $-2082 /-2078,-2064 /-2060$ and $-1910 /-1906$, leading to the negative regulation of testosterone synthesis.
\end{abstract} Key Words

- HIF1

- testosterone synthesis

- STAR

- Leydig cells
Journal of Molecular Endocrinology (2019) 62, 1-13

\section{Introduction}

Hypoxia-inducible factor-1 (HIF1), a critical transcription factor, regulates cellular hypoxic response in oxygenlacking cells and is rapidly degraded through the ubiquitinproteasome pathway under normoxic conditions (Semenza 2011, 2012, 2017, Ivan \& Kaelin 2017). HIF1 consists of two subunits, the oxygen-dependent HIF $1 \alpha$ and the stably expressed HIF1 $\beta$ (Wang et al. 1995). HIF1 $\alpha$ is hydroxylated by prolyl hydroxylase domain-containing protein 2 (PHD2) and then bound by the VHL protein, which recruits ubiquitin ligase that targets HIF $1 \alpha$ for proteasome 
degradation under well-oxygenated conditions (Ivan et al. 2001). PHD2 uses $\mathrm{O}_{2}$ and a-ketoglutarate as substrates for hydroxylation. Thus, oxygen deprivation stabilizes HIF1 protein. HIF1 $\alpha$ is also induced by deferoxamine (DFX) and cobalt chloride $\left(\mathrm{CoCl}_{2}\right)$, which inhibits hydroxylases via removing Fe(II) from the catalytic center (Kotake-Nara \& Saida 2006). It has been reported that HIF1 is associated with the initiation and development of certain diseases, including hereditary erythrocytosis, cancer, traumatic shock, pulmonary arterial hypertension and obstructive sleep apnea (Semenza 2012).

Under normal physiological conditions, HIF $1 \alpha$ is unstable in most tissues and degrades rapidly with sufficient oxygen. Thus, current knowledge about how HIF1 functions was mostly achieved in tumor cells or other pathologically hypoxic cells. One interesting phenomenon is that HIF $1 \alpha$ can be stable under physiological conditions in the testes. Marti et al. first reported that HIF1 $\alpha$ is expressed in spermatocytes, spermatids and spermatozoa in mouse testes (Marti et al. 2002). A following study reported that low partial pressure of oxygen in the testes was a stimulant of HIF1 $\alpha$ and that HIF $1 \alpha$ might play a role in spermatogenesis (Maxwell \& Salnikow 2004). It was also found that HIF1 $\alpha$ is expressed in rat testes and increased with the period of testicular ischemia (Powell et al. 2002). Furthermore, Palladino et al. identified Leydig cells, adjacent to the seminiferous tubules in the testis, as the major source of HIF1 $\alpha$ in both normoxic and hypoxic testes, suggesting that HIF1 might play a critical role in Leydig cell functions (Palladino et al. 2011). However, the mechanism of HIF1 affecting/regulating Leydig cell functions is not clearly elucidated.

The main function of Leydig cells is synthesizing and secreting testosterone, producing 95\% of the total amount in males (Svechnikov et al. 2010). Testosterone plays crucial roles in the development of secondary sex characters, maintenance of bone and sex drive (Mooradian et al. 1987). Testosterone deficiency could cause cardiovascular disease, erection dysfunction and male hypogonadism (Basaria 2014, Kloner et al. 2016, Skakkebaek et al. 2016, Elkhoury et al. 2017, Holgersson et al. 2017). Several factors such as age (Nguyen et al. 2015), exercise (Vingren et al. 2010), nutrients (Livera et al. 2002) and bodyweight (Koehler et al. 2009) affect the serum testosterone level and sexual function. Physiological testosterone level is strictly regulated by the hypothalamic-pituitarytesticular axis (Swerdloff et al. 1992). Luteotropic hormone (LH) secreted from the pituitary binds to LH/human chorionic gonadotropin (hCG) receptor and stimulates protein kinase $\mathrm{A}$ (PKA) activation through cAMP in
Leydig cells. PKA phosphorylates steroidogenic acute regulatory protein (STAR), which transports cholesterol into mitochondria, where cholesterol is transformed into pregnenolone under the catalysis of $\mathrm{P} 450$ cholesterol side chain cleavage (P450scc). Pregnenolone is converted to testosterone under the catalysis of a series of enzymes, including 3b-hydroxysteroid dehydrogenase (3b-HSD) and 17b-HSD in the smooth endoplasmic reticulum (Häggström \& Richfield 2014). Here, STAR-mediated transportation of cholesterol into mitochondia is the ratelimiting step, and thus, STAR is the rate-limiting protein for testosterone synthesis (Miller \& Bose 2011). Several proteins have been described to functionally interact with STAR for cholesterol movement across mitochondrial membranes (Bose et al. 2008, Elustondo et al. 2017). The transcriptional level of STAR directly affects the synthesis of testosterone.

Internal homeostasis of testosterone levels is of great importance to the body. Previous studies focused on the regulation of testosterone synthesis by the hypothalamicpituitary system, but little is known about the endogenous regulatory mechanism within Leydig cells. It should be noticed that a lower oxygen concentration in testical tissue was reported to cause significant reduction of serum testosterone level (Gonzales 2013). Since it is known that hypoxia can stablize HIF1 protein, we speculated that the increased HIF1 level caused a decline of testosterone synthesis, and thus, reduced the testosterone level. Star was identified as a potential target gene of HIF1 through the analysis with software JASPAR. Kowalewski et al. also reported that HIF1 binds to the Star promoter region by performing the chromatin immunoprecipitation (ChIP) assay in granulosa cells (Kowalewski et al. 2015), although the exact binding sites and function of HIF1 on Star have not been determined. Thus, HIF1 may play a key role in regulating testosterone synthesis via the transcriptional regulation of STAR in Leydig cells. The purpose of this study is to determine the binding sites and regulation mode of HIF1 for testosterone synthesis.

\section{Materials and methods}

\section{Animals and treatment}

Adult male Balb/c mice weighing 25-30g, provided by the Experimental Animal Center of Nantong University, were accommodated for 1 week before experiments with a 12-h light-dark cycle. Mice were treated in an $8.0 \% \mathrm{O}_{2}$ hypoxic chamber for 4,8 or $12 \mathrm{~h}$ ( $n=10$ for each time point) and were anaesthetized by intraperitoneal injection of chloral 
hydrate. Blood samples were collected from abdominal aorta. Testis tissues were harvested for real-time PCR, Western blot, and immunofluorescence staining. All the studies reported here were submitted to the Ethics Committee on Animal Experimentation of Nantong University and all procedures were approved according to the Animal Care and Use Committee of Nantong University and the Jiangsu Province Animal Care Ethics Committee (Approval ID: SYXK(SU)2007-0021).

\section{Cell culture}

Male Sprague-Dawley rats weighing $180-220$ g, provided by the Experimental Animal Center of Nantong University, were used for isolation of primary Leydig cells as described previously (Klinefelter et al. 1987). Decapsulated rat testes were softly digested by $0.1 \%$ collagenase at $37^{\circ} \mathrm{C}$. Then, the seminiferous tubules were removed by filtration through the 200-mesh to get cell suspension. The collected cells were resuspended in the medium of 27:3:20 (volume ratio) of Percoll: 9\% $\mathrm{NaCl}$ saline solution: DMEM-F12 medium and density gradient centrifuged at $20,000 \mathrm{~g}$ for $60 \mathrm{~min}$ at $4^{\circ} \mathrm{C}$. Isolated Leydig cells were cultured at $5 \times 10^{5}$ cells/ $\mathrm{mL}$ in DMEM-F12 medium containing 5\% newborn calf serum (Gibco) at $37^{\circ} \mathrm{C}$ in humidified atmosphere composed of $95 \%$ air and $5 \% \mathrm{CO}_{2}$ for subsequent analysis. In addition, $75 \mathrm{IU} / \mathrm{L}$ hCG were added for the stimulation of testosterone synthesis and cell growth. The cultured cells were characterized with immunofluorescence staining. Qualified cell samples should consist of more than 98\% cells positive of STAR expression.

TM3 cell line (CRL-1714, ATCC, RRID:CVCL_4326) was established from Mus musculus (mouse) and was characterized by the androgen receptor. Cells were cultured in 1:1 mixture of Ham-12 and Dulbecco's MEM, containing 5\% horse serum, $2.5 \%$ fetal bovine serum at $37^{\circ} \mathrm{C}$ in humidified atmosphere composed of $95 \%$ air and $5 \% \mathrm{CO}_{2}$. In addition, 200 IU/L hCG were added for the stimulation of testosterone synthesis.

\section{Cell treatments and transfection}

In the physical treatment group, cells were cultured in the medium which was hypoxia equilibrated for $24 \mathrm{~h}$, and were incubated in $1 \% \mathrm{O}_{2}$ and $5 \% \mathrm{CO}_{2}$ at $37^{\circ} \mathrm{C}$. In the chemical treatment groups, $200 \mu \mathrm{M} \mathrm{CoCl}_{2}$ or DFX were added into medium to induce HIF1 expression. For inhibition of HIF1 expression, TM3 cells were exposed to $200 \mu \mathrm{M}$ digoxin or shRNA at $95 \%$ air and $5 \% \mathrm{CO}_{2}$ for $2 \mathrm{~h}$ and then at $1 \% \mathrm{O}_{2}$ and $5 \% \mathrm{CO}_{2}$ for $4 \mathrm{~h}$. The supernatant was collected and used for the determination of testosterone levels, and the remaining cells were used for protein extraction, RNA extraction with TRIzol or for immunofluorescence with addition of $4 \%$ paraformaldehyde.

HEK293T cells were cultured in DMEM containing 10\% fetal bovine serum. HEK293T cells or TM3 cells were seeded in six-well plates in antibiotic-free medium the day before transfection. The constructed plasmid DNAs were transfected into HEK293T cells using Lipofectamine 2000 (11668019, Invitrogen) according to the provided instructions or transfected into TM3 cells by electroporation.

\section{Total RNA isolation and real-time PCR}

Testicular tissue total RNA was isolated by using the column animal RNAout kit (TianDZ, Beijing, China) according to the manufacturer's instructions. Cellular total RNA was isolated by TRIzol reagent. $500 \mathrm{ng}$ purified total RNA was then reverse-transcribed using HiScript 1st Strand cDNA Synthesis Kit (Vazyme, China) according to the instructions. Real-time PCR was performed using SYBR premix (Roche) with the 7500 real-time PCR system (Applied Biosystems). The reaction procedure was $98^{\circ} \mathrm{C}$ for $4 \mathrm{~min}$ followed by 40 three-step cycles of $98^{\circ} \mathrm{C}$ for $25 \mathrm{~s}, 60^{\circ} \mathrm{C}$ for $25 \mathrm{~s}$ and $72^{\circ} \mathrm{C}$ for $25 \mathrm{~s}$. All the primers used for real-time PCR are shown in Supplementary Table 1 (see section on supplementary data given at the end of this article). The relative amount of gene expression normalized to the reference gene was calculated using $\Delta \Delta \mathrm{Ct}$ method, where $\mathrm{Ct}$ is the threshold cycle of PCR reaction. The evaluation of contamination of both RNA sample and water sample were provided through agarose gel electrophoresis (Supplementary Fig. 1). PCR products were sequenced and verified (Supplementary Fig. 1). The amplification efficiency was within the scope from 0.9 to 1.1. Although we did not choose to fully present our housekeeping gene (at internal controls), we examined multiple control genes including 18s rRNA, Actb and Gapdh, which gave consistent results. In our experiments, we made sure that $\mathrm{Ct}$ for internal controls are between 14 and 17, and Ct for target genes are between 20 and 30 according to reagent manufacturer's suggestions for reliable quantification. None of the samples gave results outside those ranges.

\section{Western blot}

Testicular tissues and cells were collected in the protein extraction reagents, placed on ice for $30 \mathrm{~min}$, followed by $15,000 \mathrm{~g}$ centrifuging at $4^{\circ} \mathrm{C}$ for $15 \mathrm{~min}$. Protein 
concentration was determined by bicinchoninic acid assay. Proteins were isolated by sodium dodecyl sulfate polyacrylamide gel electrophoresis and transferred to polyvinylidene fluoride membranes using a semi-dry or wet trans-blot unit. The membranes were incubated for $1 \mathrm{~h}$ with $5 \%$ nonfat dry milk and then probed overnight at $4^{\circ} \mathrm{C}$ with anti-HIF $1 \alpha$ (GTX127309, GeneTex, AB_2616089), anti-VEGFA (\#ABS82, Millipore, AB_10806337), antiSTAR (8449, CST, AB_10889737), anti-P450scc (14217, CST, AB_2631970), anti-3beta-HSD (sc-30820, Santa Cruz, AB_2279878) and anti-B-actin (ab8227, Abcam, AB_2305186). Binding of primary antibodies was visualized with donkey anti-rabbit HRP-conjugated secondary antibody (305-005-003, Jackson, AB_2339376) or rabbit anti-goat HRP-conjugated secondary antibody (111-005-003, Jackson, AB_2337913) and the ECL-Plus system. Grayscale analysis was carried out using ImageJ (https://imagej.nih.gov/ij/).

\section{Immunofluorescence}

Cultured cells were fixed with $4 \%$ paraformaldehyde for $15 \mathrm{~min}$ at room temperature, permeablized with triton (0.1\% in TBS) for $30 \mathrm{~min}$ and blocked with 5\% BSA in PBS for $1 \mathrm{~h}$ at room temperature. Cells were then incubated overnight at $4^{\circ} \mathrm{C}$ with anti-HIF1 $\alpha$ (AF1935, R\&D, AB_355064) and anti-STAR (8449, CST, AB_10889737). Binding of primary antibodies was visualized with Alexa Fluor 488-conjugated anti-rabbit IgG (R37118, Thermo Fisher Scientific, AB_2556546) or Alexa Fluor 555-conjugated anti-goat IgG (A-21432, Thermo Fisher Scientific, AB_2535853) for $90 \mathrm{~min}$. Finally, the samples were incubated in DAPI for $10 \mathrm{~min}$ (Life Technologies) for nuclear counterstain. Paraffin-embedded testicular tissue was sectioned at $5 \mu \mathrm{m}$ following dewaxing hydration treatment for immunofluorescence staining. Images were acquired using a Leica SP8 confocal microscope with $63 \times$ oil immersion objective.

\section{Chromatin immunoprecipitation (ChIP) assay}

ChIP was performed using the SimpleChIP Enzymatic Chromatin IP Kit (Magnetic Beads) (CST, \#9003) according to the manufacturer's instructions. To crosslink proteins to DNA, TM3 cells were fixed in culture medium containing $1 \%$ formaldehyde at room temperature for $10 \mathrm{~min}$. Cells were lysed and collected, followed by adding $0.5 \mu \mathrm{L}$ of micrococcal nuclease per IP preparation and incubating for $20 \mathrm{~min}$ at $37^{\circ} \mathrm{C}$ to digest DNA to lengths of approximately $200-500 \mathrm{bp}$. The sonicated lysate was then immunoprecipitated with $2.5 \mu \mathrm{g}$ of HIF1 $\alpha$ antibody (AF1935, R\&D, AB_355064) or a negative control IgG at $4^{\circ} \mathrm{C}$ for overnight. The pulled-down chromatin was washed, reverse-cross linked and purified. The purified DNA was amplified by PCR with the corresponding primers listed in Supplementary Table 2 . The reaction procedure was $98^{\circ} \mathrm{C}$ for $5 \mathrm{~min}$ followed by 45 three-step cycles of $98^{\circ} \mathrm{C}$ for $25 \mathrm{~s}$, $60^{\circ} \mathrm{C}$ for $30 \mathrm{~s}$ and $72^{\circ} \mathrm{C}$ for $25 \mathrm{~s}$. Products were analyzed by $1.5 \%$ agarose gel electrophoresis and quantified by real-

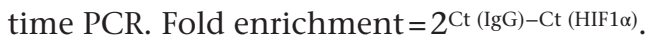

\section{Electrophoretic mobility shift assay (EMSA) and supershift assays}

EMSA was carried out to determine HIF1 interactions with putative binding elements on mouse Star promoter as previously described (Luo et al. 2003). Briefly, oligonucleotide probes with putative HIF1-binding sites on mouse Star promoter and mutations were designed, synthesized, annealed and labeled by biotin. Each probe was incubated with $5 \mu \mathrm{g}$ TM3 cell nuclear extracts (Promega) and processed for EMSA.

Supershift assays were performed as follows. In each reaction, $2.5 \mu \mathrm{g}$ of HIF1 $\alpha$ antibodies (AF1935, R\&D, AB_355064) were added to the probe/nuclear extract mixture and incubated for $20 \mathrm{~min}$ at room temperature. For competition, 100-fold excess of unlabeled cold oligo probes were incubated with nuclear extract before adding labeled oligonucleotide. Shift reactions were loaded onto $6 \%$ polyacrylamide gel and run at $170 \mathrm{~V}$ (at $4^{\circ} \mathrm{C}$ ) for $5 \mathrm{~h}$ in $0.5 \times$ TBE buffer. Results were obtained in the chemical system.

\section{Dual-luciferase reporter assays}

Fragments of mouse Star promoter region (-2227/-1893, $-1000 /+78)$ were cloned into the KpnI and HindIII restriction sites of the pGL3-basic vector (Promega). The HIF1-binding sites on mouse Star promoter were mutated respectively. All constructs were verified by sequencing.

HEK293T cells $\left(4 \times 10^{4}\right)$ were cultured in 24-well plate in antibiotic-free culture medium the day before transfection. Cells were cotransfected with 500 ng STAR reporter plasmids and $5 \mathrm{ng}$ of Renilla reporter plasmid (pRL-TK, Promega) as an internal control by Lipofectamine 2000 reagent $(1.5 \mu \mathrm{L})$ and then treated with $4 \mathrm{~h}$ hypoxia, $\mathrm{CoCl}_{2}$ or DFX. Cells were lysed and the luciferase activities were detected by Dual-Luciferase Reporter Assay System 
(Promega). Firefly luminescence signal was normalized by Renilla luminescence signal.

\section{Testosterone determination}

Mouse plasma and cell supernatant were collected and diluted to $20 \%$ according to the requirements of the instructions of the kit. The testosterone level was determined following the manufacturer's instructions of the testosterone parameter assay kit (R\&D, KGE010). First, primary antibody $(50 \mu \mathrm{L}$ per well) was incubated for $1 \mathrm{~h}$ at room temperature on a microplate shaker at $800 \mathrm{~g}$. The standard, control or sample $(100 \mu \mathrm{L}$ each) was added after three times washing. Then, testosterone conjugate $(50 \mu \mathrm{L})$ was added into each well, incubated for $3 \mathrm{~h}$ at room temperature. Finally, stop solution $(200 \mu \mathrm{L})$ was added after 30-min incubation of substrate solution.
The optical density was determined at $450 \mathrm{~nm}$ and $540 \mathrm{~nm}$ wavelengths. Standard curve was created by performing a four-parameter logistics curve-fit with Origin 8.5 (http:// www.originlab.com/). The sensitivity of testosterone assay is $0.03 \mathrm{ng} / \mathrm{mL}$. The intra-assay precision of these results is between 2.2 and $3.7 \%$, and the inter-assay precision of is between 4.2 and $5.5 \%$.

\section{Statistical analysis}

All the data were presented as mean \pm S.D. Means of two samples were compared using unpaired Student's t-test, and means of multiple groups were compared using ANOVA followed by Bonferroni's test. Differences were considered statistically significant if $P<0.05$. The statistical software used for analyzing the data was SPSS 17.0 (https:// www.ibm.com/analytics/us/en/technology/spss/).
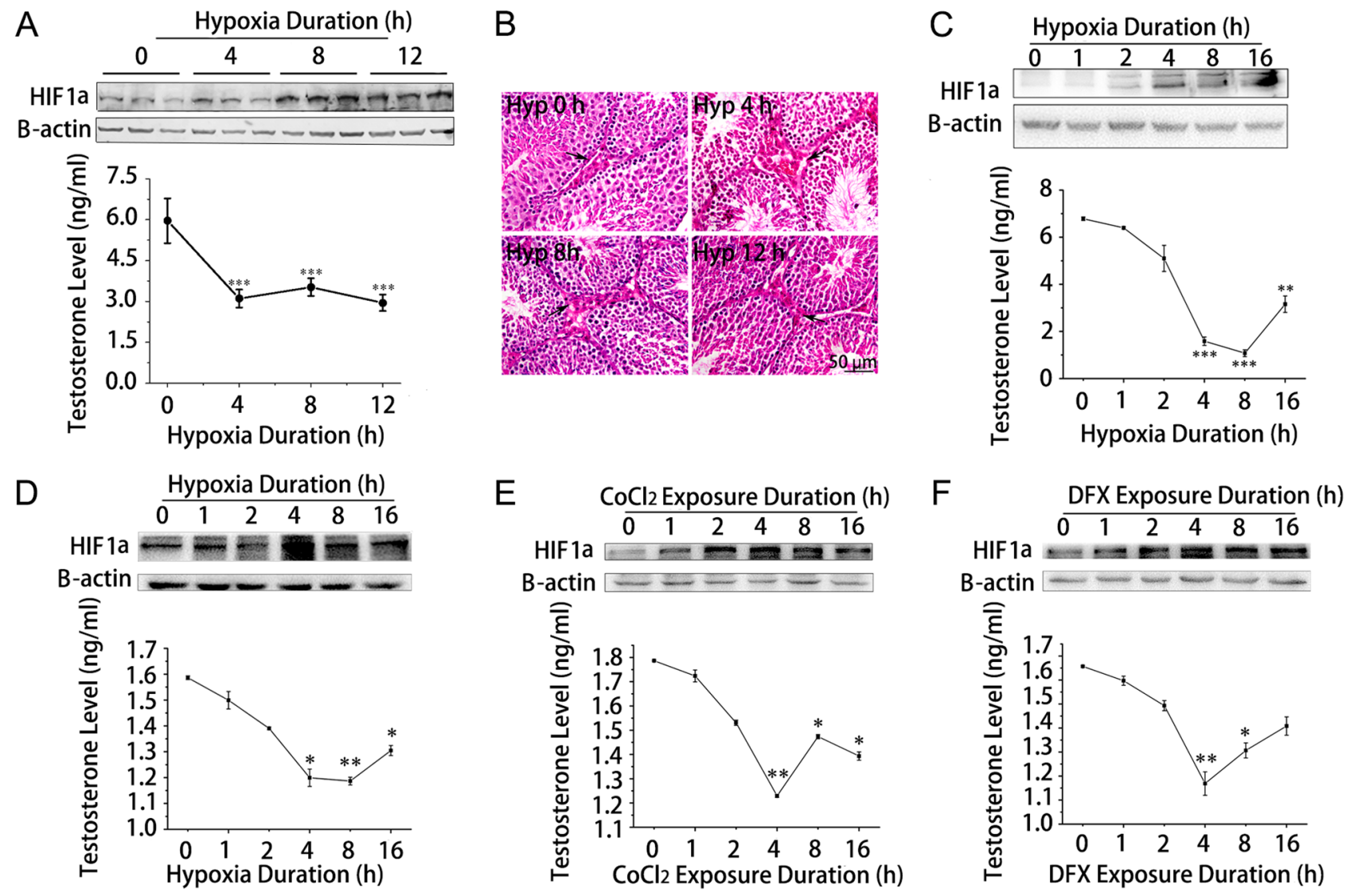

Figure 1

Testosterone level decline is accompanied by the accumulation of HIF1 $\alpha$ protein. (A) After 4-, 8- or 12-h hypoxia $\left(8 \% \mathrm{O}_{2}\right)$ treatment, mouse testis HIF1 $\alpha$ protein levels were determined by Western blot, and serum testosterone concentrations were examined by ELISA $(n=10, * \star \star P<0.001$ vs 0 h). (B) Histopathological changes were determined by H\&E staining of testis from mice after hypoxia $\left(8 \% \mathrm{O}_{2}\right)$ treatment for $0,4,8$ or $12 \mathrm{~h}(n=10)$. (C) Rat primary Leydig cells were exposed to $1 \% \mathrm{O}_{2}$ for $0,1,2,4,8$ and $16 \mathrm{~h}$. HIF1 $\alpha$ protein levels were determined by Western blot, and supernatant testosterone concentrations were examined by ELISA $\left(n=6, * P<0.05\right.$ and $* \star \star P<0.001$ vs $0 \mathrm{~h}$ ). (D, E or F) TM3 cells were exposed to $1 \% \mathrm{O}_{2}, 200 \mu \mathrm{M} \mathrm{CoCl} \mathrm{C}_{2}$ or $200 \mu \mathrm{M} \mathrm{DFX}$ for $0,1,2,4,8$ and $16 \mathrm{~h}$. HIF1 $\alpha$ protein levels were determined by Western blot, and supernatant testosterone concentrations were examined by ELISA $(n=6, * P<0.05, * \star P<0.01$, and $\star \star \star P<0.001$ vs $0 \mathrm{~h}$ ). DFX, deferoxamine. A full colour version of this figure is available at https://doi.org/10.1530/JME-18-0148. 


\section{Results}

Upregulation of HIF1 by hypoxia, DFX and $\mathrm{CoCl}_{2}$ decreases testosterone synthesis in murine Leydig cells

To evaluate the hypoxia effect on testosterone synthesis, male mice were treated with $8.0 \% \mathrm{O}_{2}$ for $0,4,8$ and $12 \mathrm{~h}$. Western blot results showed that the protein level of testis HIF1 significantly increased, while ELISA results indicated a decline trend of serum testosterone concentration (Fig. 1A). The histological structure of the testis was not significantly altered as illustrated by H\&E staining (Fig. 1B). Rat primary Leydig cells and TM3 cells were treated with $1 \% \mathrm{O}_{2}$ and both showed significant increases of HIF1 protein level and significant decline of supernatant testosterone concentration (Fig. 1C and D). To confirm that the reduction of testosterone was caused by HIF1, we added $\mathrm{CoCl}_{2}$ or DFX to stabilize HIF1 in TM3 cells and detected testosterone level in supernatant. Similar to the response to hypoxia, testosterone level significantly decreased when HIF1 increased (Fig. 1E and F), indicating that HIF1 could reduce testosterone synthesis.

\section{HIF1-induced testosterone reduction is recovered by pregenolone but not CAMP}

In testosterone synthesis pathway, cAMP is induced by LH receptor and activates PKA which then stimulates STAR phosphorylation and cholesterol transport. We added cAMP to the cell culture medium in synchronism with hypoxia $\left(1 \% \mathrm{O}_{2}\right), 200 \mathrm{nM}$ DFX, or $200 \mathrm{nM} \mathrm{CoCl}_{2}$ for $4 \mathrm{~h}$. Results showed that cAMP could not recover testosterone synthesis in these cells as in normoxic cells, indicating that the interference of HIF1 on testosterone synthesis was not prior to the transport of cholesterol (Fig. 2A). We also added pregnenolone, an intermediate product produced by p450scc in mitochondria, into cell culture medium with hypoxia, DFX or $\mathrm{CoCl}_{2}$ treatments for $4 \mathrm{~h}$, where testosterone synthesis was recovered in a dose-dependent trend, indicating that HIF1-mediated interference on testosterone synthesis was upstream of pregnenolone synthesis (Fig. 2B).

\section{HIF1 accumulation by hypoxia, DFX or $\mathrm{CoCl}_{2}$ downregulates STAR}

Next, we determined the protein and mRNA levels of factors related to testosterone synthesis after hypoxia, DFX or $\mathrm{CoCl}_{2}$ treatments in vivo and in vitro. Mice were
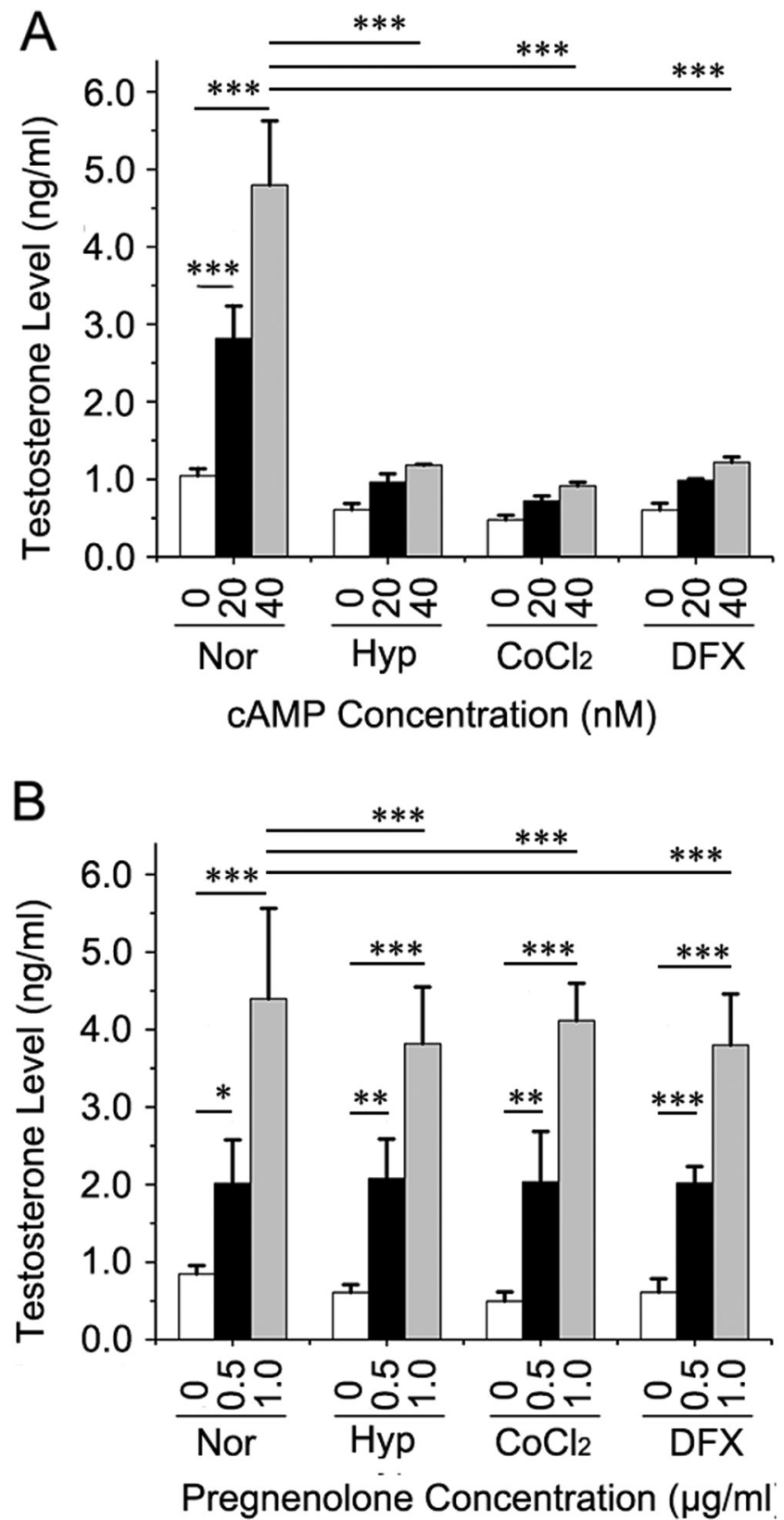

\section{Figure 2}

Testosterone decline induced by HIF1 is recovered by pregenolone but not cAMP. (A) Testosterone levels after CAMP addition in the supernatant of TM3 cells with hypoxia, $\mathrm{CoCl}_{2}$ or DFX exposure $(n=6, * \star * P<0.001)$. (B) Testosterone levels after pregenolone addition in the supernatant of TM3 cells with hypoxia, $\mathrm{CoCl}_{2}$ or DFX exposure $(n=6, * P<0.05, * \star * P<0.001)$. DFX, deferoxamine; Hyp, hypoxia; Nor, nomorxia.

exposed to $8 \% \mathrm{O}_{2}$ for $0,4,8$ and $12 \mathrm{~h}$. As shown in Fig. 3A and B, VEGF-A and HIF1 $\alpha$ in mouse testes significantly increased after hypoxia treatment $\left(8 \% \mathrm{O}_{2}\right)$. Protein and mRNA levels of STAR significantly decreased, while other factors including P450scc and 3b-HSD remained unchanged. Similarly, in both rat primary Leydig cells 
A

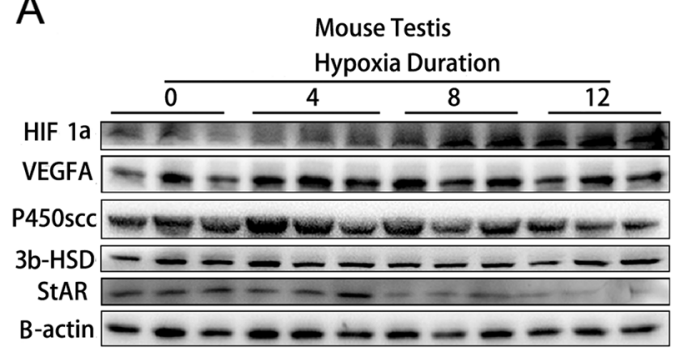

B

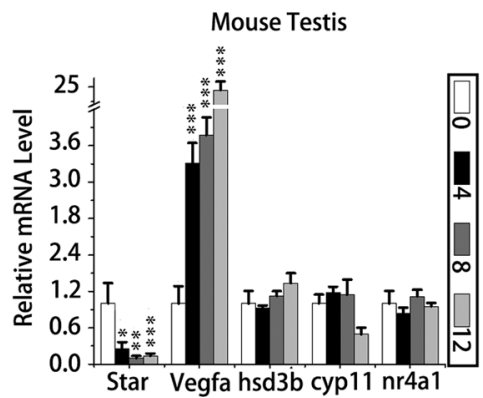

C

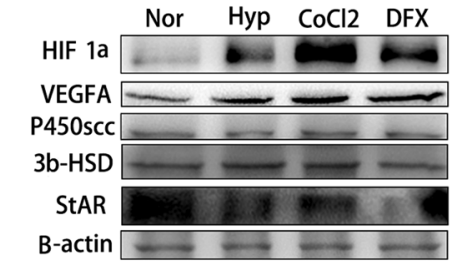

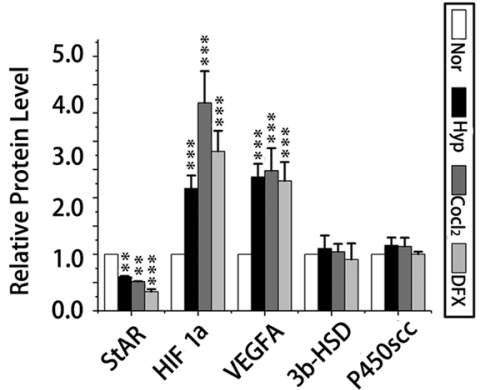

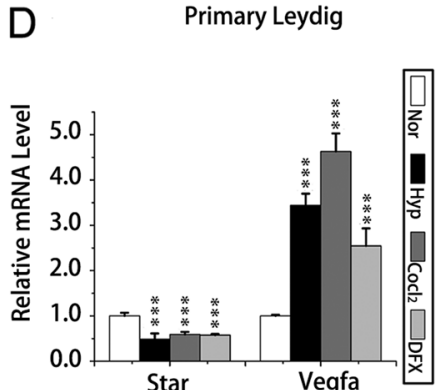

E

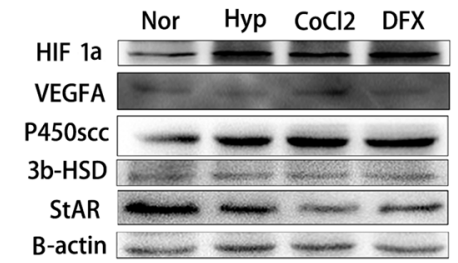

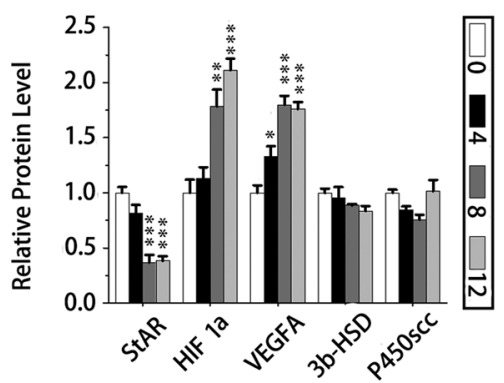

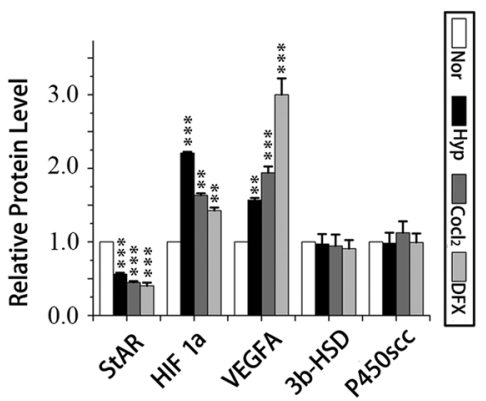

F

TM3

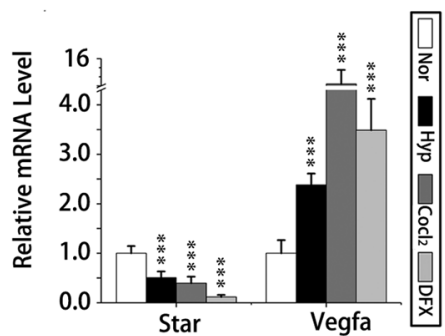

Figure 3

Changes of testosterone synthesis-related protein after hypoxia, $\mathrm{CoCl}_{2}$ or DFX treatments. (A and B) Protein levels of HIF1 $\alpha$, VEGF-A, P450scC, 3b-HSD, Star and B-actin in mouse testis were determined by Western blot, and mRNA levels of Star, hsd $3 b$, cyp 11 and $n r 4 a 1$ were detected by real-time PCR $(n=10, * P<0.05, * * P<0.01$, and $* * * P<0.001$ vs 0$)$. (C and D) Protein levels of HIF1 $\alpha$, VEGF-A, P450scC, 3b-HSD, STAR and B-actin and mRNA levels of Star and Vegfa in primary Leydig cells $(n=6, * * P<0.01$ and $* * * P<0.001$ vs 0$)$. (E and F) Protein levels of HIF1 $\alpha$, VEGF-A, P450scc, 3b-HSD, STAR and B-actin and mRNA levels of Star and Vegfa in TM3 cells $(n=6, * * p<0.01$ and $* \star * p<0.001$ vs 0$)$. DFX, deferoxamine; Hyp, hypoxia; Nor, nomorxia.

and mouse Leydig cell line TM3, $1 \% \mathrm{O}_{2}, 200 \mathrm{nM} \mathrm{CoCl}{ }_{2}$, or $200 \mathrm{nM}$ DFX for $4 \mathrm{~h}$ upregulated HIF1 $\alpha$ and VEGF-A whereas downregulated STAR, but did not affect P450scc or 3b-HSD (Fig. 3C, D, E and F).

Furthermore, immunofluorescence indicated that hypoxia, $\mathrm{CoCl}_{2}$ and DFX induced accumulation and nuclear transposition of HIF1 $\alpha$, with STAR levels depressed simultaneously in vivo (Fig. 4A) and in vitro (Fig. 4B).

\section{Repression of HIF1 $\alpha$ recovers STAR and testosterone synthesis in both normoxia and hypoxia condition}

To determine whether only HIF1 or other factors were involved in the decrease of testosterone, we repressed HIF $1 \alpha$ by PX-478 and digoxin under normoxia for 0,1 , 2, 4, 8 and $16 \mathrm{~h}$. Western blot and real-time PCR results showed a significant decrease of HIF-1 and increase of STAR, which were highest at 2 and $4 \mathrm{~h}$ (Fig. 5A and C). Testosterone level continued to rise over time (Fig. 5B). Similar results were shown when TM3 cells were exposed to HIF- $1 \alpha$ shRNA or $200 \mathrm{nM}$ digoxin under hypoxia.

While HIF1 $\alpha$ protein level significantly decreased in these cells, VEGFA mRNA level (Fig. 5E) significantly decreased. Both mRNA and protein levels of STAR (Fig. 5D) significantly increased synchronously with testosterone concentration (Fig. 5F). Immunofluorescence results confirmed that the repression of HIF1 $\alpha$ by digoxin was accompanied by an increase in STAR level (Fig. 5G). These results indicated that silencing HIF1 $\alpha$ upregulated STAR expression under normoxia and hypoxia, demonstrating HIF1 $\alpha$ as the main factor to suppress STAR. 


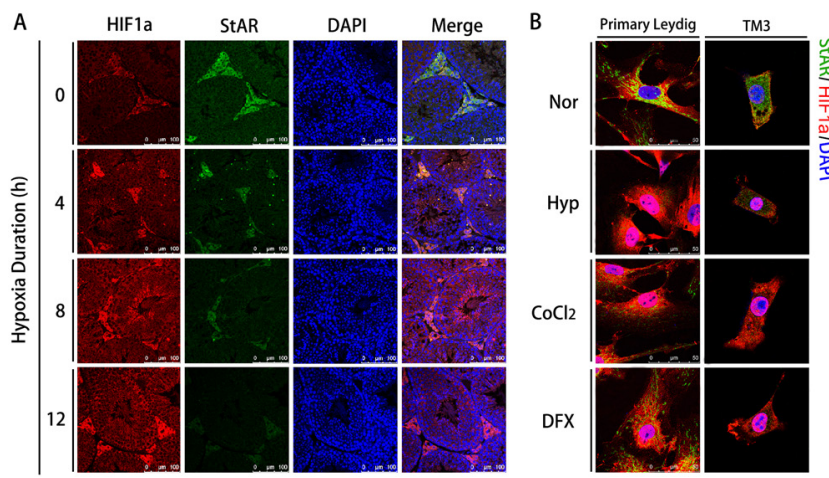

Figure 4

In situ detection of STAR and HIF1 $\alpha$ levels in Leydig cells. (A) Histological sections of mouse testis were examined by immunofluorescence $(n=10)$. (B) In situ STAR and HIF1 $\alpha$ in primary Leydig cells and TM3 cells were examined by immunofluorescence $(n=4)$. STAR was stained with Alexa 488 (green), HIF1 $\alpha$ with Alexa 555 (red), and nucleus with DAPI (blue). DFX, deferoxamine; Hyp, hypoxia; Nor, nomorxia.

\section{Identification of the HIF1-binding sites in the Star promoter region}

The abovementioned results indicated that HIF1 $\alpha$ decreased testosterone synthesis by inhibiting STAR expression in TM3 cells under hypoxia. The exact mechanism of HIF1 participation in STAR regulation was unknown. Bioinformatics analysis of JASPAR 8.0 (http:// jaspar.genereg.net/) showed that there were four predicted hypoxia response elements (HREs) in the Star promoter region, i.e. $-2082 /-2078,-2064 /-2060,-1910 /-1906$, $-215 /-218$. Probes of these target sequences (probe 1: $-2090 /-2055$, probe $2:-1920 /-1899$ and probe 3: $-222 /-201)$ were synthesized as shown in Fig. 6A. EMSA experiments were performed to evaluate the combination of HIF1 and probes. As shown in Fig. 6B, probes 1, 2 and 3 combined to the nuclear exact in line 2, 7 and 12 and were competed by cold probes in line 3, 8 and 13, indicating that all these sequences combined with HIF1 protein. However, only probes 1 and 2 combined to HIF1 in the supershift assays in line 4, 9 and 14 with addition of HIF1 $\alpha$ antibody (Fig. 6B). ChIP assay was used to confirm the binding of HIF $1 \alpha$ to the Star promoter in vivo. Agarose gel electrophoresis results indicated that HIF1 $\alpha$ co-precipitated with the DNA fragment $-2337 /-1893$ under both normoxia and hypoxia, and with the fragment $-550 /-170$ under hypoxia (Fig. 6C). Real-time PCR results showed that the fold enrichment of HIF1 $\alpha$ to IgG in $-2337 /-1893$ was above 40 times under hypoxia and 10 times under normoxia, while that in $-550 /-170$ was above six times under hypoxia and about one-fold under normoxia (Fig. 6D). To determine whether such binding of HIF1 $\alpha$ to Star promoter regions was functional, Star promoter fragments $(-2337 /-1893,-1000 /+78)$ were cloned intoluciferase reporter vector, which was transfected into HEK293T cells, followed by hypoxia $\left(1 \% \mathrm{O}_{2}\right), 200 \mathrm{nM}$ $\mathrm{CoCl}_{2}$ or $200 \mathrm{nM}$ DFX treatments. Luciferase assay results showed that upregulation of HIF $1 \alpha$ significantly decreased relative luciferase activity in HEK293T cells with luciferase under the control of Star promoter $-2337 /-1893$, while the other group of Star promoter $-1000 /+78$ did not show any significant difference (Fig. 6E).

\section{Mutations of the binding sites relieve HIF1 $\alpha$ inhibition of STAR}

To verify the specific binding between HIF1 $\alpha$ and the Star promoter region, probes with mutations in the binding sites were designed and synthesized as shown in Fig. 7A. WT probes and their mutations were incubated with nuclear exacts from hypoxia-treated TM3 cells (1\% $\mathrm{O}_{2}, 4 \mathrm{~h}$ ). EMSA results showed higher combinations of HIF1 and WT probes in hypoxia-treated TM3 cells. The binding activity of the mutated probes (mutated site 1 : -2082/-2078, mutated site 2: $-2064 /-2060$, mutated site 3: -1910/-1906) was significantly reduced compared to the WT (Fig. 7B). To determine the transcriptional activity of Star with mutations on HIF1-binding sites, luciferase reporter vectors were transfected into HEK293T cells, followed by $1 \% \mathrm{O}_{2}$ or $200 \mathrm{nM} \mathrm{CoCl}_{2}$ treatments. As shown in Fig. 7D and E, transcriptional activities of STAR with mutations on HIF1-binding sites were significantly higher than the WT. In particular, transcriptional activity of Star with mutated site $3(-1910 /-1906)$ was stronger than with two other sites (Fig. 7D and E). These results indicated that HIF1 $\alpha$ bound to the Star promoter region $-2337 /-1893$ and inhibited STAR transcription.

\section{Discussion}

In this work, we investigated the molecular mechanism for the transcriptional regulation of STAR through HIF1 and the consequent effects on the synthesis and secretion of testosterone in Leydig cells. We used physiological or chemical hypoxia $\left(\mathrm{CoCl}_{2}\right.$ or DFX) to upregulate the protein level of HIF-1. To verify the upregulation of HIF-1 regulatory pathway, we detected the expression of VEGFA, which is one of the major target genes of HIF- 1 and is the most commonly used positive reference for HIF-1 (Semenza 2001). We found that upregulation of HIF1 caused a significant decrease in STAR and testosterone both in vivo 
A
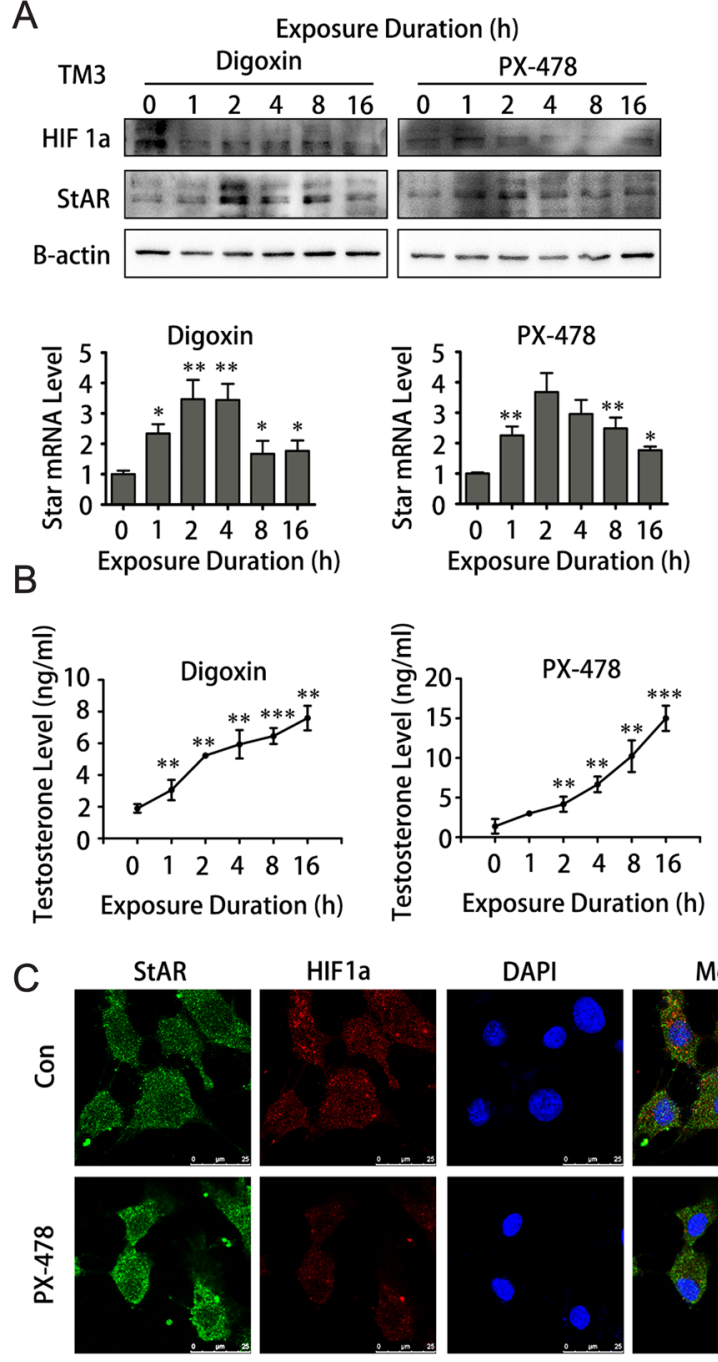
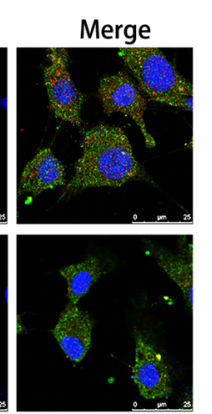

D
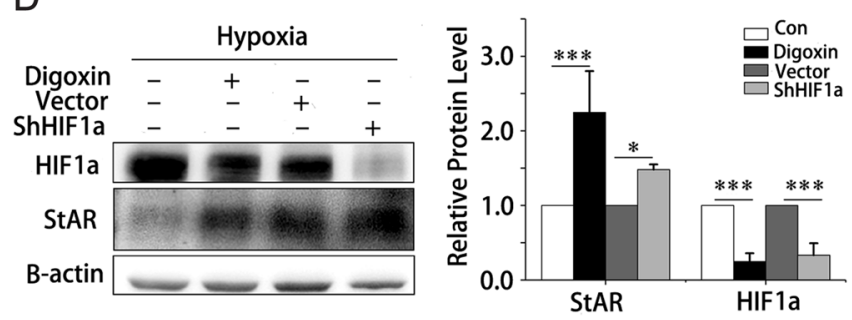

E

F
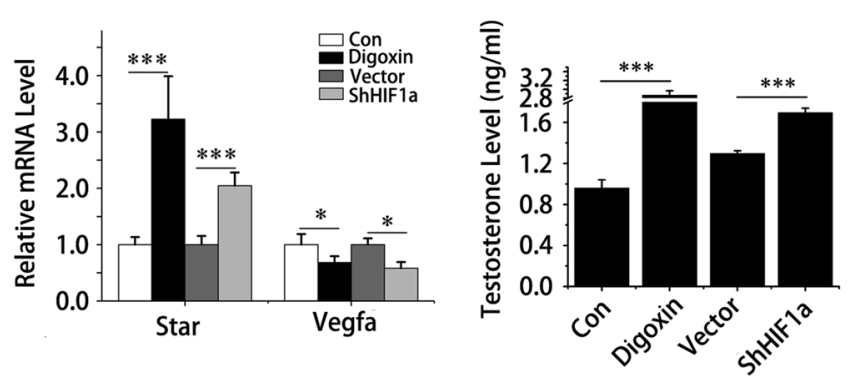

G

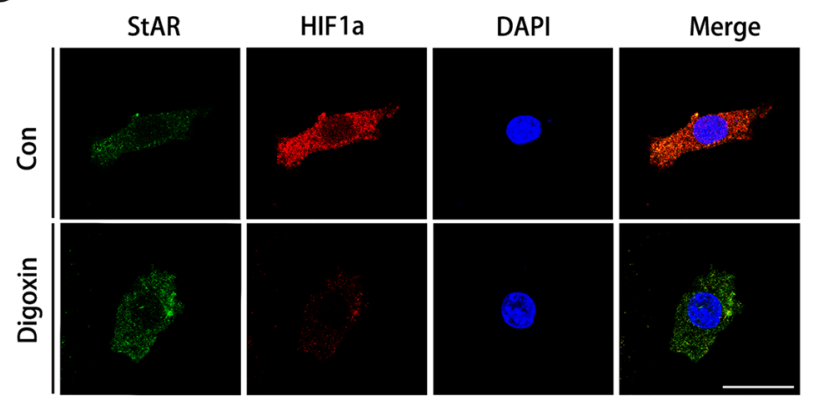

Figure 5

Repression of HIF1 upregulates STAR and testosterone. (A) Protein levels of HIF1 $\alpha$, STAR and B-actin in TM3 cells were determined by Western blot. (B) mRNA levels of Star were detected by real-time PCR and normalized to Actb ( $n=6, * P<0.05$, *** $P<0.001)$. (C) In situ STAR and HIF1 $\alpha$ in TM3 cells were examined by immunofluorescence $(n=4)$. STAR was stained with Alexa 488 (green), HIF1 $\alpha$ with Alexa 555 (red) and nucleus with DAPI (blue). (D) Protein levels of HIF1 $\alpha$, STAR, and B-actin in TM3 cells were determined by Western blot $(n=4, * P<0.05, * \star \star P<0.001)$. (E) mRNA levels of Star and Vegfa were detected by real-time PCR and normalized to Actb $(n=6, * P<0.05$, *** $P<0.001)$. (F) Testosterone levels in the supernatant of TM3 cells were determined by ELISA $(n=6, * * * p<0.001)$. (G) In situ STAR and HIF1 $\alpha$ in TM3 cells were examined by immunofluorescence $(n=4)$. STAR was stained with Alexa 488 (green), HIF1 $\alpha$ with Alexa 555 (red) and nucleus with DAPI (blue). A full colour version of this figure is available at https://doi.org/10.1530/JME-18-0148.

and in vitro. The STAR level and testosterone concentration were negatively correlated with HIF1, which is consistent with the results from Fadhillah et al. who have reported that hypoxia ( 1 and 5\% $\mathrm{O}_{2}$ ) could inhibit steroid synthesis though STAR in ovarian granulosa cells (Fadhillah et al. 2017). It was also reported that intermittent hypoxia $(10 \%$ $\mathrm{O}_{2}$ for 17 days) could cause abnormal synthesis of STAR protein and inhibit testosterone secretion in rats (Zhang et al. 2013). In vivo studies with zebrafish also showed that upregulation of HIF1 expression could inhibit the synthesis of STAR protein (Tan et al. 2017). Although these studies have proved that HIF1 represses STAR expression, the underlying molecular mechanism was not clarified. Our work reveals the exact binding sites for HIF1 on the Star promoter region (-2082/-2078, -2064/-2060 and 1910/-1906) and confirms the negatively regulatory effect of HIF1 on STAR and testosterone synthesis. One interesting finding was that a HRE in the Star promoter region $-222 /-201$ bound to HIF1, while HIF1 was not able to bind to this site and any change of HIF1 did not affect the transcription activity of this site (Fig. 6). We speculate that there might be an actual HRE in the region -222/-201 where HIF1 binding depends on the help of other DNA elements and associated protein complexes, 
A

$\begin{array}{ll} & \text { Position } \\ \text { Probe 1 } & -2090 /-2055 \\ \text { Probe 2 } & -1920 /-1899 \\ \text { Probe 3 } & -222 /-201\end{array}$

Putative HIF-1 Binding Sites agagcCCACGTGTgtctggggaaGCACGTGTaccaa ggtgtgtGCCCGTGTccettgc gccccatCTCCGTGAcccctgc

B

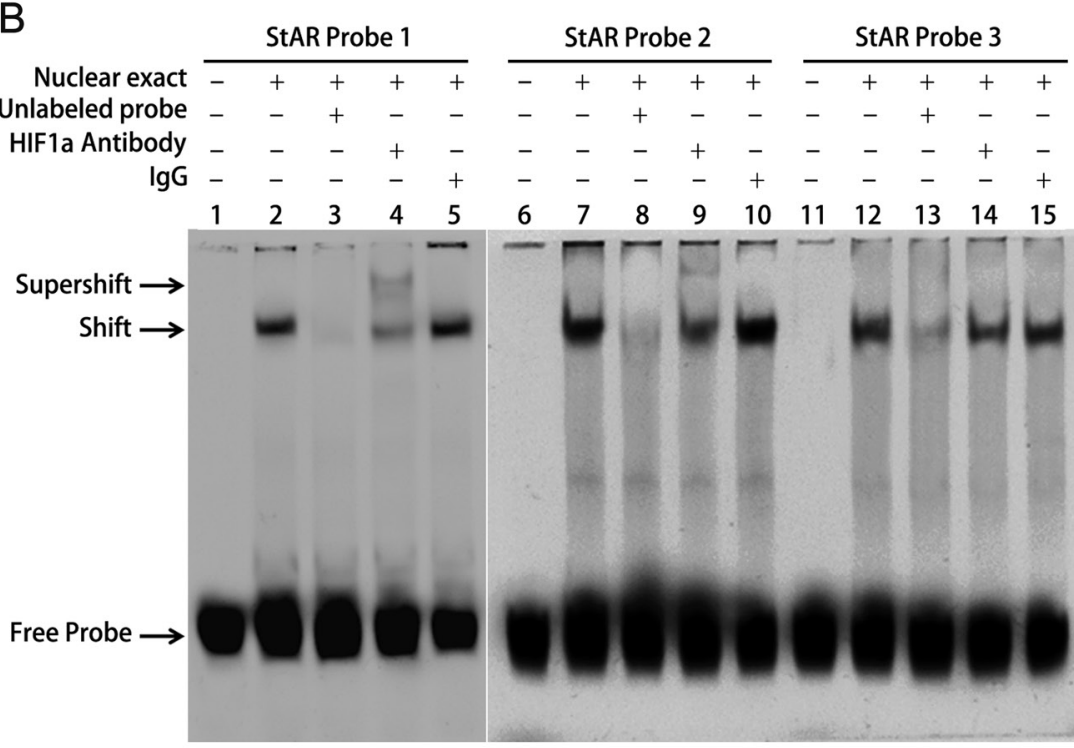

\section{C}

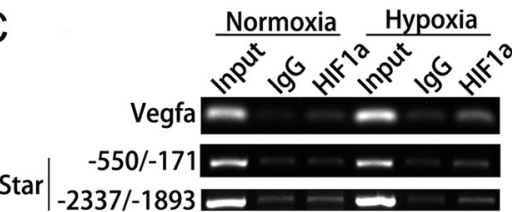

D

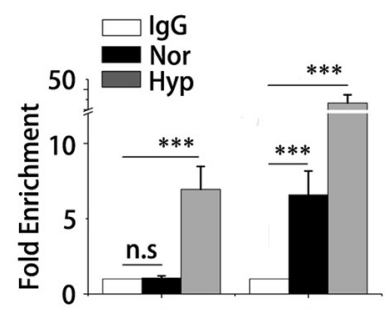

Star Promoter $-\overline{50 /-171} \quad-2 \overline{337 /-1893}$

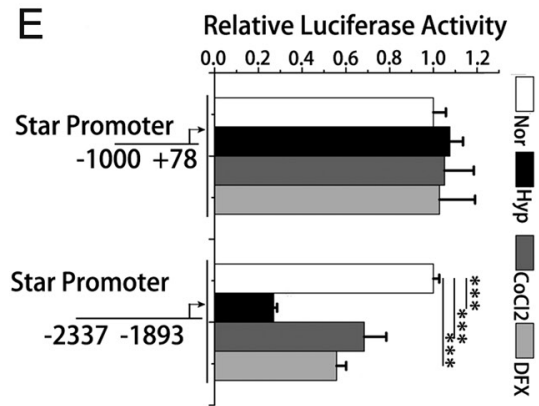

\section{Figure 6}

HIF1 $\alpha$ directly binds to the Star promoter region. (A) Probe sequences used. Numbers indicate the positions upstream of transcription start site. Capital letters show the putative HIF1-binding sites. (B) EMSA supershift experiments. Probes were labeled with biotin. Each probe was incubated with nuclear exact of TM3 cells. Shift arrows indicate the complex positions (lane 2, 7 and 12). Unlabeled probes were used as competitions and co-incubated with labeled probes and nuclear exact (lane 3,8 and 13). HIF1 antibody was added to distinguish the combinations of HIF1 and probes. Supershift arrows indicate the complex positions (lane 4, 9 and 14). IgG was added into the mixture as negative control for HIF1 antibody (lane 5, 10 and 15). (C and D) ChIP experiments. IgG groups were operated as negative controls for HIF1 groups. PCR and real-time PCR were performed to amplify the ChIP products. Numbers in C indicate positions upstream of transcription start site. Vegfa was examined as positive control for ChIP. Enrichment effects of ChIP were performed in D by comparison to IgG $(n=3)$. (E) Luciferase reporter gene assay following transient transfection with Star $(-1000 /+38 \mathrm{Luc}$ or $-2337 /-1893$ Luc). The pRL-TK vector was co-transfected to normalize transfection efficiencies. Results were presented as a luciferase/Renilla ratio $(n=6$, ***P<0.001 vs Nor). DFX, deferoxamine; Hyp, hypoxia; Nor, nomorxia.

which lie away from the region covered by the EMSA probes and the cloned promoter fragments.

It is known that HIF1 is stably expressed in Leydig cells under normal physiological conditions. We think that the transcriptional inhibitory effect of HIF-1 on STAR does not completely prevent the testosterone synthesis. The results of WB and ELISA also prove this. Stable HIF-1 expression may play a negative regulatory role in normoxic condition. Maximum decrease in testosterone concentration occurs after $4 \mathrm{~h}$ of hypoxia, $\mathrm{CoCl}_{2}$, DFX in TM3 cells and after $8 \mathrm{~h}$ of hypoxia in rat primary Leydig cells. However, the levels increase thereafter. It is interesting that the expression level of HIF-1 is also highest at $4 \mathrm{~h}$ and then gradually decreases. We speculate that the increase in testosterone after $4 \mathrm{~h}$ is due to a decrease in the level of HIF-1. Hwang et al. (2009) found intermittent hypoxia $\left(12 \% \mathrm{O}_{2}, 8 \mathrm{~h} /\right.$ day) to male rats for 4 days caused an 'increase' of plasma testosterone levels. Similar results were founded in our other study. We found intermittent hypoxia $\left(10 \% \mathrm{O}_{2}, 8 \mathrm{~h}\right.$ per day) to male mice for 1 day, the testosterone decreased. However, testosterone was recovered and increased further when mice were treated for 3-14 days. But after 28-day treatments, the serum testosterone levels were significantly decreased and continued to decline, consistent with the decrease of serum testosterone in patients with clinical respiratory disorder during sleep. We inferred that the increase in testosterone in the medium term may be a stress response.

From the synthesis of cholesterol to testosterone, there are three rate-limiting proteins, of which STAR is the first rate-limiting protein, while P450scc and 3b-HSD are the other two (Aspden et al. 1998). Previous studies reported that 3b-HSD and P450scc are target genes for HIF1 $\alpha$ in murine Leydig cells (Lysiak et al. 2009, Kumar et al. 2014). But in our work, neither protein nor mRNA levels of P450scc and 3b-HSD were significantly changed 
under hypoxia, while STAR mRNA and protein levels were significantly reduced. Addition of pregnenolone recovered the testosterone synthesis decline induced by HIF1, suggesting that the testosterone synthesis pathway in cytoplasm was not affected. One possibility is that the shorter duration of hypoxia $(4 \mathrm{~h})$ in our study was not long enough to show the regulation on 3b-HSD and P450scc levels. cAMP is an upstream signaling factor in testosterone synthesis pathway (Kolena et al. 1978). Addition of cAMP into TM3 cells did not recover testosterone synthesis, indicating the factor affected by HIF1 should be downstream of cAMP. Thus, the changes in testosterone synthesis pathway might involve cholesterol transport and pregnenolone synthesis, where STAR and p450scc are the two key factors, respectively.

External environment changes may lead to a low level of testosterone. Previous clinical work has demonstrated that respiratory hypoxia, e.g. chronic obstructive pulmonary disease (COPD), and sleep apnea are related to serum testosterone depression (Semple et al. 1980). Decreased serum testosterone level is also associated with high altitude living (Gonzales 2013), which implies that hypoxia may induce serum testosterone depression. In this study, we used hypoxia as a powerful means to increase the HIF1 level, which significantly decreased the testosterone level, consistent with clinical results (Fig. 1). It suggests the transcriptional repression of STAR by HIF1 as one mechanism for the reduction of testosterone under hypoxia condition. Hypoxia condition in tissues and organs mediated by low oxygen supply is a critical factor that affects many physiological and pathological processes, particularly in the endocrine system (Trayhurn et al. 2008, Anju et al. 2011, Olufsen \& Arukwe 2015). For instance, STAR is necessary for syntheses of steroid hormones (Sewer \& Waterman 2003). Considering that STAR not only existed in Leydig cells but also is expressed in all steroid cells including granulosa cells and adrenal cells as an essential factor in steroidogenesis from cholesterol, we infer that abnormal HIF1 levels in hypoxic tissues, tumors and degradation pathway disorders may affect steroidogenesis and thus damage endocrine system and related organs. However, it was reported that long-term exposure to the high altitude of low oxygen environment, or low blood oxygen partial pressure induced by respiratory diseases, could cause lower levels of the blood testosterone and estrogen and significantly higher corticoid and aldosterone levels (Newby et al. 2015, Verratti et al. 2017). It was inferred that HIF1-mediated STAR repression was not the only mechanism for the hypoxia-induced steroidogenesis disorder. Our other work on STAR transcriptional regulation indicated that nuclear respiratory factor 1 (NRF1) stimulated STAR transcription, which was downregulated under chronic hypoxia (Wang et al. 2017). Since NRF1 increase in adrenal gland was observed (unpublished), we infer that stimulation of STAR by NRF1 might be another mechanism underlying hypoxia-induced steroidogenesis disorder.

Steroid hormones are extremely important in circulatory system, cardiovascular system, respiratory system, reproductive system, etc. As the key male hormone, testosterone is crucial for male secondary sexual characteristics of the development, maintenance of sexual desire and skeletal muscle growth. The incidence of male COPD is much higher than that of women, and the
A

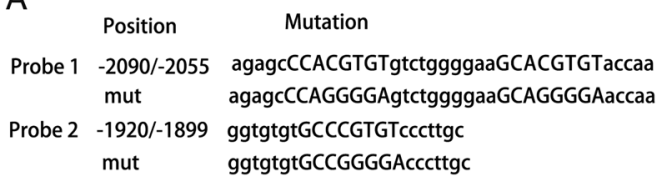

B

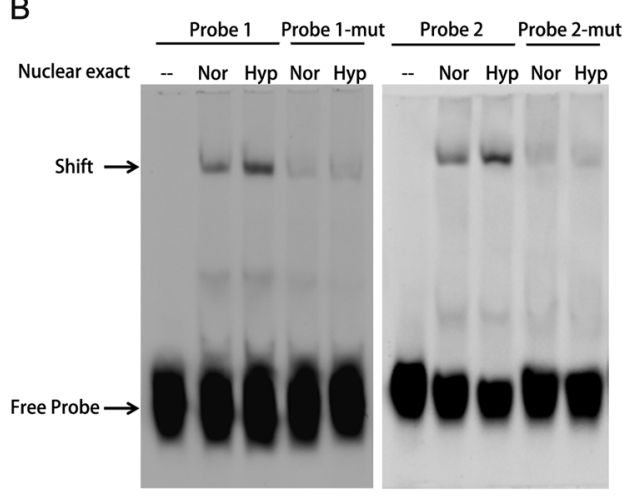

C

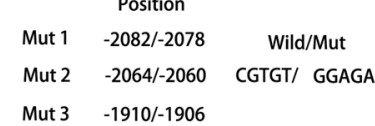

\section{D}

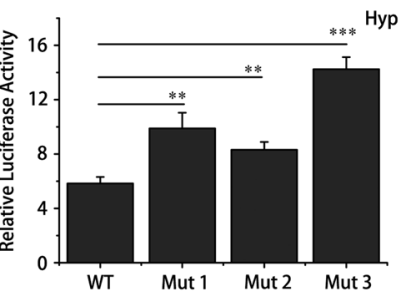

$\mathrm{E}$

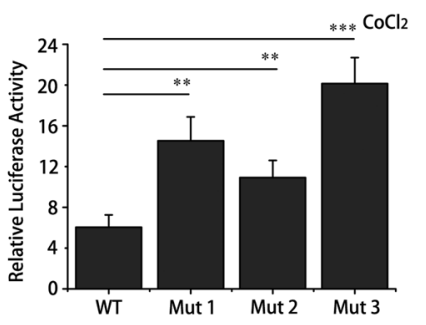

\section{Figure 7}

Binding sites of HIF1 on the Star promoter region are identified as -2082/-2078, -2064/-2060 and -1910/-1906. (A) Probe sequences. Numbers indicate positions upstream of transcription start site. Capital letters show the putative HIF1-binding sites. (B) EMSA experiments. Probes were labeled with biotin. Each probe was incubated with nuclear exact of TM3 cells. Shift arrows indicate the complex positions. Mutation probes were used to verify the specific combination. (C) Mutation sequences of putative HIF1-binding sites for Luciferase test. Numbers indicate positions upstream of transcription start site. (D and $E$ ) Luciferase reporter gene assay following transient transfection with Star (-2337/-1893Luc) and its mutations. The $\mathrm{pRL-TK}$ vector was co-transfected to normalize transfection efficiencies. Cells were treated with $1 \% \mathrm{O}_{2}$ or $200 \mathrm{nM} \mathrm{CoCl}$. Results were presented as a luciferase/Renilla ratio $(n=6$, $* * P<0.01, * * * P<0.001)$. 
severity of disease is positively correlated with the decrease of testosterone level (Semple et al. 1980). Our study of the reduction of testosterone secretion by HIF1 provides a new insight into the entire testosterone synthesis disorder field. Although the testosterone replacement therapy has made great development, the clinical effects still need to be improved. We will further study the effects of testosterone on the pathogenesis of COPD, in order to provide new ideas for the clinical treatment.

\section{Supplementary data}

This is linked to the online version of the paper at https://doi.org/10.1530/ JME-18-0148.

\section{Declaration of interest}

The authors declare that there is no conflict of interest that could be perceived as prejudicing the impartiality of the research reported.

\section{Funding}

The study was supported by the National Natural Science Foundation of China (31471141, 31500965, 31671206, 31701049, 81702874), the Priority Academic Program Development of Jiangsu Higher Education Institution (PAPD), University Science Research Project of Jiangsu Province (15KJB180012), the Natural Science Foundation of Jiangsu Province (BK20150404), the Postgraduate Research \& Practice Innovation Program of Jiangsu Province (YKC16022) and Jiangsu Overseas Visiting Scholar Program for University Prominent Young \& Middle-aged Teachers and Presidents.

\section{Acknowledgements}

The authors thank Dr Xiaomei Wu and Dr Qianqian Luo who kindly gave proposals to the study. In addition, they thank Longlu Pan and Liuhan Jin for the primary exploration works.

\section{References}

Anju T, Nandhu MS, Jes P \& Paulose C 2011 Endocrine regulation of neonatal hypoxia: role of glucose, oxygen, and epinephrine supplementation. Fetal and Pediatric Pathology 30 338-349. (https:// doi.org/10.3109/15513815.2011.587498)

Aspden WJ, Rodgers RJ, Stocco DM, Scott PT, Wreford NG, Trigg TE, Walsh J \& D'Occhio MJ 1998 Changes in testicular steroidogenic acute regulatory (STAR) protein, steroidogenic enzymes and testicular morphology associated with increased testosterone secretion in bulls receiving the luteinizing hormone releasing hormone agonist deslorelin. Domestic Animal Endocrinology 15 227-238. (https://doi. org/10.1016/S0739-7240(98)00013-7)

Basaria S 2014 Male hypogonadism. Lancet 383 1250-1263. (https://doi. org/10.1016/s0140-6736(13)61126-5)

Bose M, Whittal RM, Miller WL \& Bose H 2008 Steroidogenic activity of STAR requires contact with mitochondrial VDAC1 and phosphate carrier protein. Journal of Biological Chemistry 283 8837-8845. (https://doi.org/10.1074/jbc.M709221200)
Elkhoury FF, Rambhatla A, Mills JN \& Rajfer J 2017 Cardiovascular health, erectile dysfunction, and testosterone replacement: controversies and correlations. Urology 110 1. (https://doi. org/10.1016/j.urology.2017.07.030)

Elustondo P, Martin LA \& Karten B 2017 Mitochondrial cholesterol import. Biochimica et Biophysica Acta: Molecular and Cell Biology of Lipids 1862 90-101. (https://doi.org/10.1016/j.bbalip.2016.08.012)

Fadhillah, Yoshioka S, Nishimura R, Yamamoto Y, Kimura K \& Okuda K 2017 Hypoxia-inducible factor 1 mediates hypoxia-enhanced synthesis of progesterone during luteinization of granulosa cells. Journal of Reproduction and Development 63 75-85. (https://doi. org/10.1262/jrd.2016-068)

Gonzales GF 2013 Serum testosterone levels and excessive erythrocytosis during the process of adaptation to high altitudes. Asian Journal of Andrology 15 368-374. (https://doi.org/10.1038/aja.2012.170)

Häggström M \& Richfield D 2014 Diagram of the pathways of human steroidogenesis. WikiJournal of Medicine $\mathbf{1}$ 5. (https://doi. $\operatorname{org} / 10.15347 / \mathrm{wjm} / 2014.005)$

Holgersson MB, Malm J \& Giwercman YL 2017 Serum testosterone levels in early prediction of prostate cancer risk. European Urology $\mathbf{7 1}$ 992-994. (https://doi.org/10.1016/j.eururo.2016.11.037)

Hwang GS, Chen ST, Chen TJ \& Wang SW 2009 Effects of hypoxia on testosterone release in rat Leydig cells. American Journal of Physiology: Endocrinology and Metabolism 297 E1039-E1045. (https://doi. org/10.1152/ajpendo.00010.2009)

Ivan M \& Kaelin WG Jr 2017 The Egln-HIF $\mathrm{O}_{2}$-sensing system: multiple inputs and feedbacks. Molecular Cell 66 772-779. (https://doi. org/10.1016/j.molcel.2017.06.002)

Ivan M, Kondo K, Yang H, Kim W, Valiando J, Ohh M, Salic A, Asara JM, Lane WS \& Kaelin WG 2001 HIF-1 $\alpha$ targeted for VHL-mediated destruction by proline hydroxylation: implications for $\mathrm{O}_{2}$ sensing. Science 292 464-468. (https://doi.org/10.1126/science.1059817)

Klinefelter GR, Hall PF \& Ewing LL 1987 Effect of luteinizing hormone deprivation in situ on steroidogenesis of rat Leydig cells purified by a multistep procedure. Biology of Reproduction 36 769-783. (https:// doi.org/10.1095/biolreprod36.3.769)

Kloner RA, Carson C, Dobs A, Kopecky S \& Mohler ER 2016 Testosterone and cardiovascular disease. Journal of the American College of Cardiology 67 545-557. (https://doi.org/10.1016/j.jacc.2015.12.005)

Koehler K, Parr MK, Geyer H, Mester J \& Schänzer W 2009 Serum testosterone and urinary excretion of steroid hormone metabolites after administration of a high-dose zinc supplement. European Journal of Clinical Nutrition 63 65-70. (https://doi.org/10.1038/sj. ejcn.1602899)

Kolena J, Seböková E \& Jezová-Repceková D 1978 Gonadotropin receptors, cAMP and testosterone in estrogenized male rats. Experientia 34 266-267. (https://doi.org/10.1007/BF01944719)

Kotake-Nara E \& Saida K 2006 Endothelin-2/vasoactive intestinal contractor: regulation of expression via reactive oxygen species induced by $\mathrm{CoCl}_{2}$, and Biological activities including neurite outgrowth in PC12 cells. Scientific World Journal 6 176-186. (https:// doi.org/10.1100/tsw.2006.37)

Kumar A, Rani L \& Dhole B 2014 Role of oxygen in the regulation of Leydig tumor derived MA-10 cell steroid production: the effect of cobalt chloride. Systems Biology in Reproductive Medicine 60 112-118. (https://doi.org/10.3109/19396368.2013.861034)

Livera G, Rouiller-Fabre V, Pairault C, Levacher C \& Habert R 2002 Regulation and perturbation of testicular functions by vitamin A. Reproduction 124 173-180. (https://doi.org/10.1530/rep.0.1240173)

Luo Q-Q, Wang D, Yu M-Y \& Zhu L 2003 Effect of hypoxia on the expression of proliferating cell nuclear antigen and phenotype of cardiac fibroblasts. International Union of Biochemistry and Molecular Biology Life 63 120-128. (https://doi.org/10.1002/iub.419)

Lysiak JJ, Kirby JL, Tremblay JJ, Woodson RI, Reardon MA, Palmer L \& Turner T 2009 Hypoxia-inducible factor-1 alpha is constitutively expressed in murine Leydig cells and regulates 3 beta-hydroxysteroid 
dehydrogenase type 1 promoter activity. Journal of Andrology $\mathbf{3 0}$ 146-156. (https://doi.org/10.2164/jandrol.108.006155)

Kowalewski MP, Gram A \& Boos A 2015 The role of hypoxia and HIF1alpha in the regulation of STAR-mediated steroidogenesis in granulosa cells. Molecular and Cellular Endocrinology 401 35-44. (https://doi.org/10.1016/j.mce.2014.11.023)

Marti HH, Katschinski M Dr, Wagner KF, Schäffer L, Stier B \& Wenger RH 2002 Isoform-specific expression of hypoxia-inducible factor-1alpha during the late stages of mouse spermiogenesis. Molecular Endocrinology 16 234-243. (https://doi.org/10.1210/ mend.16.2.0786)

Maxwell P \& Salnikow K 2004 HIF-1: an oxygen and metal responsive transcription factor. Cancer Biology and Therapy 3 29-35. (https://doi. org/10.4161/cbt.3.1.547)

Miller WL \& Bose H 2011 Early steps in steroidogenesis: intracellular cholesterol trafficking. Journal of Lipid Research 52 2111-2135. (https://doi.org/10.1194/jlr.R016675)

Mooradian AD, Morley JE \& Korenman SG 1987 Biological actions of androgens. Endocrine Reviews 8 1-28. (https://doi.org/10.1210/ edrv-8-1-1)

Newby EA, Kaushal KM, Myers DA \& Ducsay CA 2015 Adrenocorticotropic hormone and PI3K/Akt inhibition reduce eNOS phosphorylation and increase cortisol biosynthesis in long-term hypoxic ovine fetal adrenal cortical cells. Reproductive Sciences 22 932-941. (https://doi.org/10.1177/1933719115570899)

Nguyen CP, Hirsch MS, Moeny D, Kaul S, Mohamoud MA \& Joffe HV 2015 Testosterone and 'age-related hypogonadism' - FDA concerns. New England Journal of Medicine 373 689-691. (https://doi. org/10.1056/Nejmp1506632)

Olufsen M \& Arukwe A 2015 Endocrine, biotransformation, and oxidative stress responses in salmon hepatocytes exposed to chemically induced hypoxia and perfluorooctane sulfonamide (PFOSA), given singly or in combination. Environmental Science and Pollution Research 22 17350-17366. (https://doi.org/10.1007/s11356014-3847-y)

Palladino MA, Pirlamarla PR, Mcnamara J, Sottas CM, Korah N, Hardy MP, Hales DB \& Hermo L 2011 Normoxic expression of hypoxia-inducible factor 1 in rat Leydig cells in vivo and in vitro. Journal of Andrology 32 307-323. (https://doi.org/10.2164/ jandrol.110.011494)

Powell JD, Elshtein R, Forest DJ \& Palladino MA 2002 Stimulation of hypoxia-inducible factor-1 alpha (HIF-1alpha) protein in the adult rat testis following ischemic injury occurs without an increase in HIF-1alpha messenger RNA expression. Biology of Reproduction $\mathbf{6 7}$ 995-1002. (https://doi.org/10.1095/biolreprod.101.002576)

Semenza GL 2001 HIF-1 and mechanisms of hypoxia sensing. Current Opinion in Cell Biology 13 167-171. (https://doi.org/10.1016/S09550674(00)00194-0)

Semenza GL 2011 Oxygen sensing, homeostasis, and disease. New England Journal of Medicine 365 537-547. (https://doi.org/10.1056/ NEJMra1011165)

Semenza GL 2012 Hypoxia-inducible factors in physiology and medicine. Cell 148 399-408. (https://doi.org/10.1016/j. cell.2012.01.021)
Semenza GL 2017 Hypoxia-inducible factors: coupling glucose metabolism and redox regulation with induction of the breast cancer stem cell phenotype. EMBO Journal 36 252-259. (https://doi. org/10.15252/embj.201695204)

Semple PDA, Beastall GH, Watson WS \& Hume R 1980 Serum testosterone depression associated with hypoxia in respiratory failure. Clinical Science 58 105-106. (https://doi.org/10.1042/ cs0580105)

Sewer MB \& Waterman MR 2003 ACTH modulation of transcription factors responsible for steroid hydroxylase gene expression in the adrenal cortex. Microscopy Research and Technique 61 300-307. (https://doi.org/10.1002/jemt.10339)

Skakkebaek NE, Meyts ER-D, Louis GMB, Toppari J, Andersson A-M, Eisenberg ML, Jensen TK, Jørgensen N, Swan SH, Sapra KJ, et al. 2016 Male reproductive disorders and fertility trends. Physiological Reviews 96 55-97. (https://doi.org/10.1152/physrev.00017.2015)

Svechnikov K, Landreh L, Weisser J, Izzo G, Colon E, Svechnikova I \& Söder O 2010 Origin, development and regulation of human Leydig cells. Hormone Research in Paediatrics 73 93-101. (https://doi. org/10.1159/000277141)

Swerdloff RS, Wang C-C \& Bhasin S 1992 Developments in the control of testicular function. Bailliere's Clinical Endocrinology and Metabolism 6 451-483. (https://doi.org/10.1016/S0950-351X(05)80158-2)

Tan T, Yu RMK, Wu RSS \& Kong RYC 2017 Overexpression and knockdown of hypoxia-inducible factor 1 disrupt the expression of steroidogenic enzyme genes and early embryonic development in zebrafish. Gene Regulation and Systems Biology 11 1-11. (https://doi. org/10.1177/1177625017713193)

Trayhurn P, Wang B \& Wood IS 2008 Hypoxia and the endocrine and signalling role of white adipose tissue. Archives of Physiology and Biochemistry 114 267-276. (https://doi. org/10.1080/13813450802306602)

Verratti V, Ietta F, Paulesu L, Romagnoli R, Ceccarelli I, Doria C, Illic GF, Giulio CD \& Aloisi AM 2017 Physiological effects of high-altitude trekking on gonadal, thyroid hormones and macrophage migration inhibitory factor (MIF) responses in young lowlander women. Physiological Reports 5 e13400. (https://doi.org/10.14814/phy2.13400)

Vingren JL, Kraemer WJ, Ratamess N, Anderson J, Volek JS \& Maresh CM 2010 Testosterone physiology in resistance exercise and training: the up-stream regulatory elements. Sports Medicine $\mathbf{4 0}$ 1037-1053. (https://doi.org/10.2165/11536910-000000000-00000)

Wang GL, Jiang B, Tue EA \& Semenza GL 1995 Hypoxia-inducible factor 1 is a basic-helix-loop-helix-PAS heterodimer regulated by cellular $\mathrm{O}_{2}$ tension. PNAS 92 5510-5514. (https://doi.org/10.1073/ pnas.92.12.5510)

Wang X, Pan L, Zou Z, Wang D, Lu Y, Dong Z \& Zhu L 2017 Hypoxia reduces testosterone synthesis in mouse Leydig cells by inhibiting NRF1-activated STAR expression. Oncotarget 8 16401-16413. (https:// doi.org/10.18632/oncotarget.14842)

Zhang GL, Dai DZ, Zhang C \& Dai Y 2013 Apocynin and raisanberine alleviate intermittent hypoxia induced abnormal STAR and 3betaHSD and low testosterone by suppressing endoplasmic reticulum stress and activated p66Shc in rat testes. Reproductive Toxicology 36 60-70. (https://doi.org/10.1016/j.reprotox.2012.12.002)

Received in final form 8 October 2018

Accepted 18 October 2018

Accepted Preprint published online 18 October 2018 